\title{
Family Medicineand Family medicine training in China:
community Heatrith crisis and opportunity
}

\author{
Masahiro J Morikawa
}

To cite: Morikawa MJ. Family medicine training in China: crisis and opportunity. Fam Med Com Health 2020;8:e000283. doi:10.1136/fmch-2019-000283

Received 05 November 2019 Revised 10 January 2020 Accepted 15 January 2020

\section{Check for updates}

(c) Author(s) (or their employer(s)) 2020. Re-use permitted under CC BY-NC. No commercial re-use. See rights and permissions. Published by BMJ.

Family Medicine, University of Virginia, Charlottesville, Virginia, USA

Correspondence to

Professor Masahiro J Morikawa; mm7jc@virginia.edu

\section{STRENGTHENING PRIMARY CARE THROUGH FAMILY MEDICINE}

Primary care based in the community centres has been one of the top priorities in healthcare reform in China launched in 2009. ${ }^{1}$ In order to support the reform, hospital spending has been curved to put more resources at the primary care level. ${ }^{2}$ Recent review, however, still argues slow progress in developing primary care system in China. ${ }^{3}$ Studies have pointed out that primary care has not been the first point of contact for majority of patients in China. ${ }^{4}$ Beijing ecology of care study ${ }^{5}$, for example, demonstrated fewer number of people seek primary care physicians in the community as their first contact care compared with a similar study conducted in the USA. People prefer tertiary care hospitals in urban centres for their first contact care. ${ }^{6}$

Historically, larger proportion of population live in villages were covered by 'barefoot' doctors $^{7}$ with minimal but practical medical training throughout the country. As the life style change with rapid and massive urbanisation, the demand of primary care rapidly shifted from community medicine, encompassing from immunisation to health education for the mass, to a new role accommodating individualised comprehensive medical care assuring the well-being of individuals and families in the context of resources of the community. ${ }^{8}$ This is how family medicine fits in the new primary care model in China.

The attempt to retrain large number of primary care providers into family physician has met numerous problems; level of education varies among providers at primary care level $^{9}$; low motivation for retraining ${ }^{10}$ due to insufficient support from the system. ${ }^{11}$ Low level of education, low financial support and high demand from the system ${ }^{12}$ drive primary care providers to migrate into better pays leaving their posts in rural communities ${ }^{13}$ or leave them with low morale and motivation. ${ }^{14}$ Subsequently, tertiary care medical centres in cities continue to be packed with patients with primary care needs. ${ }^{15}$ Without any good role model and support system, it is hard to attract sufficient number of students into primary care. ${ }^{16}$

\section{FAMILY MEDICINE TRAINING IN CHINA}

Currently, there are three pathways to train family physicians in China. ${ }^{17}$ Residency training programme (so-called $5+3$ programme) consists of 5-year medical school plus 3-year family medicine residency training becomes a gold standard. ${ }^{18}$ Retraining programme which offers conversion of existing primary care providers in the community to become family physicians and scholarship programme including rural-oriented tuition-waived medical education programme, which recruits primary care-minded high school students with tuition waiver for medical school and a pledge to serve for rural practice. ${ }^{19}$ Rapid expansion of those training programme has their own limitations: $5+3$ programme can only supply fraction of total primary care providers annually; scholarship programme is yet to attract more students to make a difference in rural primary care.$^{20}$ And, the retraining programme is still requiring national standard and monitoring system of the quality of training. ${ }^{21}$ Three issues should be addressed with the standardisation and monitoring of the retraining programme ${ }^{22}$ First, the benefit of retraining should be clarified in terms of their financial and social benefit. ${ }^{23}$ Second, we should articulate how to overcome serious shortage of teachers in primary care to train more primary care providers. Third, instead of defining the length of the retraining, we should introduce more flexible topic and competency-based credit programme to help them to convert to family physicians. We also should look for positive outliers, who excel their performance and study their reasons for success. Online-based and app-based training and support can be a powerful tool to assist retraining strategy for busy practitioners in communities. ${ }^{24}$ 


\section{HOW WE TURN THE CRISIS INTO AN OPPORTUNITY?}

The Chinese character means crisis also be read as opportunity. What can we suggest to turn the crisis into opportunity for thriving family medicine in China? There are two level of arguments: programme level and administrative level.

For the programme level, first, one of the goals in the current reform is to establish general practice as an academic discipline at university level ${ }^{25}$ to create primary care as an academic discipline. What is urgently needed is instructions of practical knowledge and skills through hands-on, goaloriented training beyond conventional teaching methods. Lecture-heavy teaching style is also not conducive for casebased and problem-based learning, which requires discussions among the group.

Second, in the era of chronic diseases and management through informed consent and shared decision making, health coach roles should be emphasised in their training and that role may be played well with retrained primary care providers with rich life experiences. Similarly, we should incorporate the concept of team-based care, care coordination and continuity of care as important elements of disease management in the era of multiple comorbidities in the era of chronic illnesses.

Third, if retraining is to be the main venue to boost the number of primary care providers, we should not focus on length-based training. Rather we should implement competency-based training programme, which is flexible for the length. Learners in different level of skills can flexibly learn with their own pace to accumulate family medicine-specific education credits to be qualified. This approach might broaden the door to providers with diverse background and their daily workload. Fourth, we should demonstrate and teach bedside skills and physical examination, rather than exacerbating over-reliance to diagnostic modalities, such as blood work, imaging studies.

For the administrative level, first, the goal of our effort to assist primary care building in China should be clarified. Our motivation to assist China's effort is not simply duplicating our style of family medicine in China, but family medicine appropriately adapted in their healthcare system and fully integrated into primary care system. Second, therefore, our focus is to train primary care providers, not necessarily family medicine residents after their medical school as new graduates. Third, our target audience of our training might not be our own equivalent with MD degrees, but coming from various backgrounds and experiences. Fourth, in order to align our effort to achieve their goal and assure appropriate allocation of resources, we need their national-level coordination for foreign collaborators. And finally, our efforts among different institutions should be standardised so that we can avoid unnecessarily duplication.

\section{Contributors MJM is solely responsible for the content.}

Funding The authors have not declared a specific grant for this research from any funding agency in the public, commercial or not-for-profit sectors.

Competing interests None declared.
Patient consent for publication Not required.

Provenance and peer review Not commissioned; externally peer reviewed.

Open access This is an open access article distributed in accordance with the Creative Commons Attribution Non Commercial (CC BY-NC 4.0) license, which permits others to distribute, remix, adapt, build upon this work non-commercially, and license their derivative works on different terms, provided the original work is properly cited, appropriate credit is given, any changes made indicated, and the use is non-commercial. See: http://creativecommons.org/licenses/by-nc/4.0/.

\section{REFERENCES}

1 Cheng J-M, Yuan Y-X, Lu W, et al. Primary health care in China: is China's health reform reform for the whole nation? Prim Health Care Res Dev 2017;18:398-403.

2 Atella V, Brugiavini A, Pace N, et al. The health care system reform in China: effects on out-of-pocket expenses and saving. China Economic Review 2015;34:182-95.

3 Yip W, Fu H, Chen AT, et al. 10 years of health-care reform in China: progress and gaps in universal health coverage. The Lancet 2019;394:1192-204.

4 Wu D, Lam TP, Lam KF, et al. Health reforms in china: the public's choices for first-contact care in urban areas. Fam Pract 2017;13:cmw133-200.

5 Shao S, Zhao F, Wang J, et al. The ecology of medical care in Beijing. PLoS One 2013;8:e82446.

6 Sun Xet al. Factors associated with the choice of primary care facilities for initial treatment Amon rural and urban residents in southwestern China. IBiD 2019.

7 Li LA. The edge of expertise: representing barefoot doctors in cultural revolution China. Endeavour 2015;39:160-7.

8 Mash R, Almeida M, Wong WCW, et al. The roles and training of primary care doctors: China, India, Brazil and South Africa. Hum Resour Health 2015;13:93.

9 Wong WCW, Zhu S, Ong JJ, et al. Primary care workforce and continuous medical education in China: lessons to learn from a nationwide cross-sectional survey. BMJ Open 2017;7:e015145.

$10 \mathrm{Gu}$ J, Zhen T, Song Y, et al. Job satisfaction of certified primary care physicians in rural Shandong Province, China: a cross-sectional study. BMC Health Serv Res 2019;19:75.

$11 \mathrm{Li} \mathrm{X,} \mathrm{Lu} \mathrm{J,} \mathrm{Hu} \mathrm{S,} \mathrm{et} \mathrm{al.} \mathrm{The} \mathrm{primary} \mathrm{health-care} \mathrm{system} \mathrm{in} \mathrm{China.} \mathrm{The}$ Lancet 2017;390:2584-94.

12 Hung L-M, Shi L, Wang $\mathrm{H}$, et al. Chinese primary care providers and motivating factors on performance. Fam Pract 2013;30:576-86.

13 Meng Q, Yuan J, Jing L, et al. Mobility of primary health care workers in China. Hum Resour Health 2009;7:24.

14 Zhang M, Wang W, Millar R, et al. Coping and compromise: a qualitative study of how primary health care providers respond to health reform in China. Hum Resour Health 2017;15:50.

15 Maignan M. China's Health System Reform and Medical Education. JAMA 2009;302:1270-1.

16 Liang D, Tang C-X. The specialty choice of medical students in China: a stated preference experiment. BMC Med Educ 2016;16:107.

17 Dai H, Fang L, Malouin RA, et al. Family medicine training in China. Fam Med 2013;45:341-4.

18 Hou J, Michaud C, Li Z, et al. Transformation of the education of health professionals in China: progress and challenges. The Lancet 2014;384:819-27.

19 Pei H, Sun Y, Bai Z, et al. Selective admission policy of medical undergraduates in Western China: applicants' real attitudes to the choice of a rural medical career. Rural Remote Health 2018;18:4519.

20 Liu J, Zhang K, Mao Y, et al. Attitude towards working in rural areas: a cross-sectional survey of rural-oriented tuition-waived medical students in Shaanxi, China. BMC Med Educ 2018;18:91.

21 Kong $X$, Yang Y. The current status and challenges of community general practitioner system building in China. QJM 2015;108:89-91.

22 Li T, Lei T, Xie Z, et al. Determinants of basic public health services provision by village doctors in China: using non-communicable diseases management as an example. BMC Health Serv Res 2015;16:42

23 Song K, Scott A, Sivey P, et al. Improving Chinese primary care providers' recruitment and retention: a discrete choice experiment. Health Policy Plan 2015;30:68-77.

24 Zhang Z, Zhan X, Li Y, et al. Web-based training for primary healthcare workers in rural China: a qualitative exploration of stakeholders' perceptions. PLoS One 2015;10:e0125975.

25 Liu Q, Wang B, Kong Y, et al. China's primary health-care reform. The Lancet 2011;377:2064-6. 